\title{
Application and Research of Web-based Short Message Platform in Campus Network
}

\author{
Hanguo Mao ${ }^{1}$, Lanyou $\mathrm{Li}^{1}$, Li Chen ${ }^{1}$ \\ ${ }^{1}$ Nanjing Institute of Technology, Nanjing, 211167, China
}

Keywords: Short message platform; Campus network; Application; Research

\begin{abstract}
This paper mainly researches various kinds of application of web-based short message platform in campus network. Those applications are developed by use of various kinds of computer networking technologies and communication technologies according to the practical experience in campus network. Through establishing web-based short message platform in campus network, it is able to realize easier communication and help communication between student and student, student and teacher, and teacher and teacher, and this application is a historical reform of digitalized management of school; through application of modern digitized education mode in teaching process, it is able to provide timely and convenient mutual communication platform for teachers and students.
\end{abstract}

\section{Receiving mode and application of web short message in campus network}

In the modern digitalized campus network platform, the main access ways include the access via web, and the access via customer service terminal of computers in campus network. The main application is shown as below.

\section{Relationship between receiving and sending of traditional mails and short message notification platform}

The receiving of traditional mails can be completed via computer network; in case of no computer, the receiving and checking of some important mails may be delayed, such as checking meeting notice and scheduling; furthermore, such process takes a long time. However, if we receive the mails via short message platform, we can timely and quickly check the mails.

The receiving of short message is closely related to current mobile, telecom, and Unicom network. The basic parameters for operation of short message platform system, and the requirement for importing and maintaining users' basic information can supervise the system and make statistics of various aspects of data business. The administrator in short message platform is responsible for managing and supervising all individual users, such as making mass texting and checking information; however, as for general users, they can log in the system to check personal information, modify the password, and bind with cell phone only after registration. The menu of application functions may be different for different users.

\section{Release, inquiry, interaction, and reserved management of short message in campus} network

The basic web access can let various kinds of users directly release the information on the browser, which is both time-saving and labor-saving; this is the most basic method of surfing the internet and applicable to communication among teachers and students in campus network. For example, through release some exam information, guidance information, information related to exam, and enterprise recruitment information, each student of the school can timely look up to the information related to themselves and it is able to let students who will graduate not miss the job opportunity provided by each enterprise, that is, improving employment rate of school and reducing the cost budget of each department. Besides, we can also directly release and receive relevant information on service terminal. For example, we can use the code to quickly look up telephone number, time and place of class; after each exam, the students can also inquire their result via code. The short message platform not only can let us release and receive any information, but also can carry out online direct communication; for example, we can have interactive communication in campus network and forum. The short message notification platform can also play an appointment function and we can complete 
the appointment on the computer or through short message by use of web way so that the students can know the lecture of academic report, interested books, and the students who will participate in employment can check recruitment time and place for convenience of ensuring timely information transfer; through web way, we can timely and quickly know and master various kinds of information we need. However, as for web-based management, we can log in the platform after registered authorization, that is, ensure that each user' information is safe and confidential, and then we can check historical log via platform management. Besides, the short message platform can provide us with diversified ringing sound and games and enrich our campus life.

\section{Function of short message platform digitalized service in campus}

Constructing digitalized campus is an important engineering in current China's educational reform process. In the modern education, the digitalized teaching promotes rapid development of education. With continuous reform of modern information-based construction, the information service plays a bigger and bigger role in school teaching, management, and scientific research.

Due to rapid development of computer network, quickening the construction of application of digitalized teaching has become an important engineering at present. The short message platform service depends on internet and has quick speed of information spreading. Due to the development of communication industry, the short message gradually becomes a kind of means through which people implement their activities; due to the convenience and quickness, the short message plays a bigger and bigger function in people's activities.

The digitalized campus construction is established based on information and computer network technology and it mainly focuses on collecting and processing information related to teaching, student's information management, and campus cultural life; the digitalized teaching is a kind of virtualized teaching process in modern network. From teaching equipments to teaching management, the digitalized management is fully applied to virtually establish a space in traditional campus teaching. The web access can let us quickly and conveniently look up relevant information, which further improves the teaching efficiency of campus, finally realizes generalization of all teaching information in education process, and provides school with rich data. On one hand, it reduces operational cost of school; on the other hand, it improves the purpose of digitalized teaching.

\section{Exploration on web short message platform in open campus education}

\section{Basic framework and function of short message platform}

Because most of students are not in school as for open education, the information spreading is very important. In the campus education, the application of short message platform is mainly divided into three parts. Firstly, it is the prompt of teaching information. In the teaching process, the short message can help to remind students of daily teaching notices and make students know their learning plan, curriculum schedule, and learning data. Except for learning-related information, the information also includes notice of beginning of term, vacation, and activities; through receiving and sending short message, it is able to realize timely communication between teachers and students. Secondly, it is the management of students' information, mainly including importing, inquiring, modifying, and printing all students' all information so as to provide convenience for administers to manage and maintain each student's information. Thirdly, it is the access to short message platform. Currently, there are three roles, all of which need registered login and take responsibility of canceling the access permission.

\section{Security of web-based short message platform}

The web-based short message platform mainly adopts the unified identity authentication platform to carry out access control and management; before use, each users can log in the platform after identity authentication; otherwise they will be unable to check relevant information. In this way, it is able to greatly reduce the disclosure of information and ensure the security of personal information. 


\section{Influence of short message platform digitalized construction in campus and teaching exploration}

Currently, in China's higher education, the traditional teaching mode we can see has far lagged behind the teaching mode in other developing countries. Firstly, in the teaching, we shall regard modernized information development as primary goal. In current schools, the great changes have happened in students' way of life and learning, and the rapid development of information technology causes great change in school education and the information technology becomes an important strategic resource in education and teaching reform and development. Faced with rapid production of massive information, the schools shall consider how to transform current teaching and what is the difference between current and traditional education and teaching. In the past, the teachers could easily give a lesson as long as they carefully prepared lessons and spent much time finding information in advance. However, currently, with the rapid development of social information technology, the students can also collect large quantity of information compared to teachers, and the students' application of information technology is improved step by step. In a sense, the students are advantageous over teachers in terms of technical application. Under this condition, the teachers shall think about how to apply the digitalized teaching into education. In the process of constructing digitalized platform, the schools shall perfect various kinds of information. Under the background of modern information-based education, it is required to slowly change teachers' traditional teaching opinions and methods, change students' learning way, and change school rules so as to enhance the interactive communication on platform and make use of information-based teaching to change current school environment. In this process, the schools shall be equipped with various kinds of resources, establish course teaching platform, change work process, and enhance various kinds of training. Through integration of point and sphere, we can improve the development of digitalized education step by step. It is believed that we will establish a kind of new education mode with strong teaching quality, and strong application ability of information technology which can be rapidly accepted by students, and establish a professional teacher team which have firm basic knowledge, conforms to the demand of modern social development, and adapt to reform trend of new curriculum materials in the near future.

With rapid development of application of information technology, the interactive platform can help us to carry out timely online communication and also become a "common meal" in students and teachers' learning and work, all of which will promote the school to continuously develop toward the teaching purpose of “improve teachers and students' morality, improve teaching quality, improve school-running taste, and enhance school brand”. In this way, the teaching quality is improved and the talents are cultivated.

In the process of realizing information-based construction, the school shall establish a teaching team with high information accomplishment as key work content of school; however, with the development of modern information technology and network technology, the certain challenge is brought to some teachers in traditional teaching while they face new educational mode. Under the background of information-based teaching, the teachers shall continuously take charging study upon facing new educational mode. On one hand, with the arrival of modern information era, the higher learning requirement has been proposed for teachers' single development; on the established information platform, the teachers shall continuously improve their self-cultivation, keep the attitude of active learning, and then improve their skills in application of information technology so that they can improve their comprehensive ability in classroom; on the other hand, the teachers shall have the ability to carry out learning, mutual communication, and sharing with others so as to form a kind of new teaching method with information technology and network technology education. In the teaching environment of new era, this is the primary necessary condition for a qualified teacher, and this also provides conditions for later teaching construction, easily and conveniently applying various kinds of computer, network, multi-media equipments, and various kinds of relevant information under information resource environment, and improving teachers' professional development. Therefore, it can be seen that the teachers' improvement of their professional quality under 
environment of basic modern information technology and network technology is not only the demand of contemporary social development, but also necessary in historical development.

In school digitalized education, all works and teaching can't be separated from the support of modern technical environment. We firstly experience of preliminary introduction, transformation, and improvement, and then experience the transition of relationship between teachers and students, equalized and democratic mutual relation, mutual cooperation, and win-win and sharing rules, which lays a firm foundation for the formation of modern teaching. The teachers are making efforts to improve their professional development in information technology, and the students are also making efforts to carry out conscious and independent study under the information-based environment, etc.

In modern schools, the teachers are making efforts to carry out continuous exploration and summary in practice process, and participate in school teaching, management, evaluation and study, work, and life, further reflect the school construction under the information-based environment, carry out learning and communication on platform and exploration and research on multi-media applied learning. For example, we can make use of the wide application of Microblog platform and $\mathrm{Bb}$ platform; make use of $\mathrm{Bb}$ platform to support the teaching video process of off-line review, explanation of key points, and after-class reference learning; make use of platform to carry out learning, statistics, and tutorship via online exam simulation; utilize teaching application of various kinds of multi-media. Then, as for those applications and teaching cases, the teaching cases conducted on school Bb platform and classical cases summarized in teaching process, ordinary work experience accumulated, the teachers carry out quick ideological conversion under information-based environment, and explore new teaching methods in teaching. Although it is a small part, the experience accumulation and significance can bring great changes to the reform of digitalized education. We can make use of teaching development of new mode to realize further improvement of teaching method under information-based environment and further transformation on modern education of schools.

\section{Conclusion}

With rapid development of computer in modern society, tight cooperation between campus network with mobile, Unicom, and telecom business, diversified short message value-added services, application of web-based service platform, it is able to timely and quickly provide each users with service, thus we have dependency on them and our initiative is enhanced. The construction method of digitalization also appears in an endless way. Nevertheless, the short message platform provides us with a convenient and quick way of information communication, release, and spreading; it realizes maximum interest via minimum investment and obtains a good effect in campus.

\section{Acknowledgments}

This paper belongs to Nanjing Institute of Technology; project name: Research and Application of Web Service-based Digital Campus Short Message Platform; serial number: QKJB201313; fund applicant: Mao Hanguo.

\section{References}

[1] Xiong Xianfang: Application and Research of Web-based Short Message Platform in Campus Network, Computer Knowledge and Technology, 2008, 2 (10): 56-58.

[2] Xu Yanfa: Application of Web-based Short Message Management Platform in Campus Network, Heilongjiang Science and Technology Information, 2008, (35): 86. 